\title{
Computer Simulation of Adaptive Control Algorithms for AC Wind Turbine with DFIG
}

\author{
Andrey A. Mazalovi, a \\ ${ }^{1}$ South federal university in Taganrog, Rostov region, Chekhova st.,22, Taganrog, 347942 , Russian \\ Federation. \\ aAnmaz8@list.ru
}

Keywords: wind power plant, adaptive control, doubly-fed electric machine, non-linear control system

\begin{abstract}
Nowadays actual scientific problem of renewable energy is the problem of developing control systems, that ensure the generation of stable voltage in a changing environment. This paper presents a structure and methods of synthesis of control system development, which allow to decide the indicated problem. An electric subsystem of wind power plant is a well-known structure with well-known advantages, consisting mainly of double-fed induction generator (DFIG) and power converter in the circuit of rotor. Operation of the control system based on the original nonlinear mathematical model of DFIG in rotational "dq" coordinates, taking into account the nonlinear external and internal DFIG disturbances, such as inductances of coil winding, changes of coil winding resistances from temperature, etc. The study received mathematical model, adaptive control algorithms and its computer simulation of the wind turbine with DFIG.
\end{abstract}

\section{Introduction}

An increasing requirement in energy resources at unstable oil prices stimulate to search the alternative decisions of power problems. One of the most successfully developed types of alternative energy is wind power. Its rapid growth observed in the world, proofing an attractiveness of this technology. It is expressed in the purity, reliability and input speed. So, according to Global Wind Energy Council (GWEC), to the end of 2015 global wind power capacity will reach 609 GW, compared to 237. 4 gigawatts at the end of 2011. The three leading world markets remain the China, U. S. and Europe.

In recent years, the rapid growth of installed wind power capacity turned out to be possible through the development and implementation of new technological solutions, one of which is DFIG used as generator in wind power plants(WPP). Such DFIG are widely used in powerful WPP, as they allow to convert the available wind energy more efficiently, especially in periods of weak winds.

It is known that the parameters of the generated voltage depends on terms of environment. At the same time, the necessity of quality stable voltage generation sets the problem of technological decisions development, allowing to minimize influence of different factors on output voltage quality. Such a technological solution is adaptive control system (CS) of a WPP with DFIG, permitting high speed reaction to wind speed changes and the rate of the connected electrical load, thus maintaining the stability of the generator output voltage. Synthesizing an adaptive high-speed CS and using the structure of WPP with DFIG it becomes possible to design and build these types of wind turbines.

\section{Synthesis of nonlinear CS}

Nonlinear CS control law. The solution of the indicated problem, offered in this paper, is based on the nonlinear model of DFIG in rotational "dq" coordinates, as in the conditions of different disturbances, linearizing appears uneffective [1]. Because, coming from the structure of WPP, control circuit is a rotor circuit, then primary control objective is feed on it control voltage of some parameters, at that DFIG output voltage remains unchanging and corresponds to set, without depending on influences. As it applies to a model, it is necessary to get the control values of voltages 
on the "dq" rotor axes $V_{d r}$ and $V_{q r}$, at the well-known required stator voltages $V_{d s}^{r e f}$ and $V_{q s}^{\text {ref }}$. The classic mathematical model of DFIG does not take into account the nonlinear changes of its parameters, such as winding inductances, changes of winding resistances from temperatures etc., accepting their permanent, that is not quite right. Meantime, in real DFIG such changes have an influence on control quality, so the synthesis of control system, which is taking into account such nonlinear disturbances, is an actual task. The disturbances arising up from nonlinear character of the control object are difficult to mathematical description, however valuation of these disturbances with the subsequent bringing of adjustments in work of CS on the basis of such estimation is a fully solvable task. For this purpose, in the standard mathematical model of DFIG we will add some functions of immeasurable disturbances, $f_{d 1}$ and $\mathbf{f}_{\mathrm{d} 2}$ (Eq.1), accordingly for the stator $\mathrm{d}$ and $\mathrm{q}$ axes currents, and next we synthesize control laws.

$$
\left[\begin{array}{c}
\frac{d}{d t} i_{q s}=\frac{L_{r}\left(V_{q s}-R_{s} * i_{q s}\right)}{-L_{r} L_{s}+L_{m}^{2}}+\frac{L_{m}\left(\omega_{r}\left(L_{r} i_{d r}+L_{m} i_{d s}\right)-R_{r} i_{q r}+V_{q r}\right.}{-L_{r} L_{s}+L_{m}^{2}}+f_{d 1} \\
\frac{d}{d t} i_{d s}=-\frac{L_{r}\left(V_{d s}-R_{s} i_{d s}\right)}{-L_{r} L_{s}+L_{m}^{2}}+\frac{L_{m}\left(\omega_{r}\left(L_{r} i_{q r}+L_{m} i_{q s}\right)-R_{r} i_{d r}+V_{d r}\right.}{-L_{r} L_{s}+L_{m}^{2}}+f_{d 2} \\
\frac{d}{d t} i_{q r}=-\frac{L_{m}\left(V_{q s}-R_{s} i_{q s}\right)}{-L_{r} L_{s}+L_{m}^{2}}-\frac{L_{s}\left(\omega_{r}\left(L_{r} i_{d r}+L_{m} i_{d s}\right)-R_{r} i_{q r}+V_{q r}\right.}{-L_{r} L_{s}+L_{m}^{2}} \\
\frac{d}{d t} i_{d r}=-\frac{L_{m}\left(V_{d s}-R_{s} i_{d s}\right)}{-L_{r} L_{s}+L_{m}^{2}}-\frac{L_{s}\left(\omega_{r}\left(L_{r} i_{q r}+L_{m} i_{q s}\right)-R_{r} i_{q r}+V_{q r}\right.}{-L_{r} L_{s}+L_{m}^{2}}
\end{array}\right]
$$

In detail, mathematical derivation of control laws see in [1]. So, in accordance with [1], we will get:

$$
\begin{aligned}
& V_{d r}=-\frac{1}{L_{m} R_{n}}\left(f_{d 2} L_{r} L_{s} R_{n}+f_{d 2} L_{m}^{2} R_{n}-R_{n} L_{r} V_{d s}+R_{s} L_{r} R_{n} i_{d s}-L_{r} R_{n} \omega_{r} L_{m} i_{q r}-\right. \\
& \left.-\omega_{r} L_{m}^{2} i_{q s} R_{n}-R_{n} L_{m} R_{r} i_{d r}-a_{1} L_{r} L_{s} R_{n} i_{d s}+a_{1} L_{m}^{2} R_{n} i_{d s}+a_{1} V_{d s}^{r e f}\left(L_{r} L_{s}-L_{m}^{2}\right)\right) ; \\
& \mathrm{V}_{\mathrm{qr}}=\frac{1}{\mathrm{~L}_{\mathrm{m}} \mathrm{R}_{\mathrm{n}}}\left(-\mathrm{f}_{\mathrm{d} 1} \mathrm{~L}_{\mathrm{r}} \mathrm{L}_{\mathrm{s}} \mathrm{R}_{\mathrm{n}}+\mathrm{f}_{\mathrm{d} 1} \mathrm{~L}_{\mathrm{m}}^{2} \mathrm{R}_{\mathrm{n}}+\mathrm{R}_{\mathrm{n}} \mathrm{L}_{\mathrm{r}} \mathrm{V}_{\mathrm{qs}}-\mathrm{R}_{\mathrm{s}} \mathrm{L}_{\mathrm{r}} \mathrm{R}_{\mathrm{n}} \mathrm{i}_{\mathrm{qs}}-\mathrm{L}_{\mathrm{r}} \mathrm{R}_{\mathrm{n}} \omega_{\mathrm{r}} \mathrm{L}_{\mathrm{m}} \mathrm{i}_{\mathrm{dr}}-\right. \\
& \left.-\omega_{\mathrm{r}} \mathrm{L}_{\mathrm{m}}^{2} \mathrm{i}_{\mathrm{ds}} \mathrm{R}_{\mathrm{n}}+\mathrm{R}_{\mathrm{n}} \mathrm{L}_{\mathrm{m}} \mathrm{R}_{\mathrm{r}} \mathrm{i}_{\mathrm{qr}}+\mathrm{a}_{1} \mathrm{~L}_{\mathrm{r}} \mathrm{L}_{\mathrm{s}} \mathrm{R}_{\mathrm{n}} \mathrm{i}_{\mathrm{qs}}-\mathrm{a}_{1} \mathrm{~L}_{\mathrm{m}}^{2} \mathrm{R}_{\mathrm{n}} \mathrm{i}_{\mathrm{qs}}+\mathrm{a}_{1} \mathrm{~V}_{\mathrm{qs}}^{\mathrm{ref}}\left(-\mathrm{L}_{\mathrm{r}} \mathrm{L}_{\mathrm{s}}+\mathrm{L}_{\mathrm{m}}^{2}\right)\right) ;
\end{aligned}
$$

Values of the required voltages $V_{d s}^{r e f}$ and $V_{q s}^{\text {ref }}$ set through Park-Gorev transformations from "abc" coordinates to "dq".

Synthesis of observer. Now, in accordance with [2], we will execute a procedure of synthesis for $\mathbf{f}_{d 1}$ and $\mathbf{f}_{\mathrm{d} 2}$ disturbances observer, influencing on currents in stator windings, because from their values depends the value of DFIG output voltage. In detail, mathematical derivation of observer equalizations see in [1]. Now we can define equalization of observer :

$$
\begin{aligned}
& \hat{f}_{d 1}=a_{1 \mathrm{H}} I_{q S}+\hat{z}_{1} \\
& \hat{f}_{d 2}=a_{2 \mathrm{H}} I_{d s}+\hat{z}_{2}
\end{aligned}
$$

These disturbances estimations are used in close control system, built on preset systems principle with indirect adaptation to disturbances. Eq. 2 and Eq. 3 are equalizations of voltage regulator with the estimation of disturbances.

\section{Computer simulation}

MATLAB was chosen as an appropriate computer simulation tool. Note that the main idea of the proposed method is the nonlinear unaccountable disturbances inclusion into model and estimation of 
such disturbances, and based on this estimation to make a correction when working adaptive control system. The model of adaptive nonlinear control system consist of two m-file, the first of which describes used constants and variables, specify the conditions of calling the built-in MATLAB functions, processed the results and built the required graphics. The second file is an $\mathrm{m}$-file to calculate the right parts of the differential equations, described by formulas (2), (3), (4) and (5), in accordance with the syntax and call rules of these functions in MATLAB. Let disturbances be the change of electric load and frequency of DFIG shaft rotation.

So, let us set the required parameters of the generated voltage amplitude $220^{*} \sqrt{ } 2$ volts and frequency of 50 Hertz. Let at time 0.01 second, the electric load has changed, and at the time 0.02 frequency of shaft rotation.

Figure 2 shows 4 charts, allowing to evaluate the quality of adaptive nonlinear control system with the observer. We see that the form of a voltage stator in "dq" axis is smooth, without strong distortions, that is a result of adaptive control systems with observer operation. At time 0.02 second, we asked the change in the mechanical moment on the generator shaft, which corresponds to increased wind and the shaft rotation speed also gradually, began to increase, which is reflected on the corresponding graph.

The currents of the rotor, which is also the stimulation and control currents, has changed their form, in particular the amplitude and frequency, depending on external disturbances, which is a consequence of adaptive control system operation, and the most appreciable break curve is observed at the moment of time 0.01 seconds, that is corresponds to a spike load. As the shaft rotation speed varies smoothly, and control system, adapting, also changes the voltage, and therefore the rotor currents smoothly.
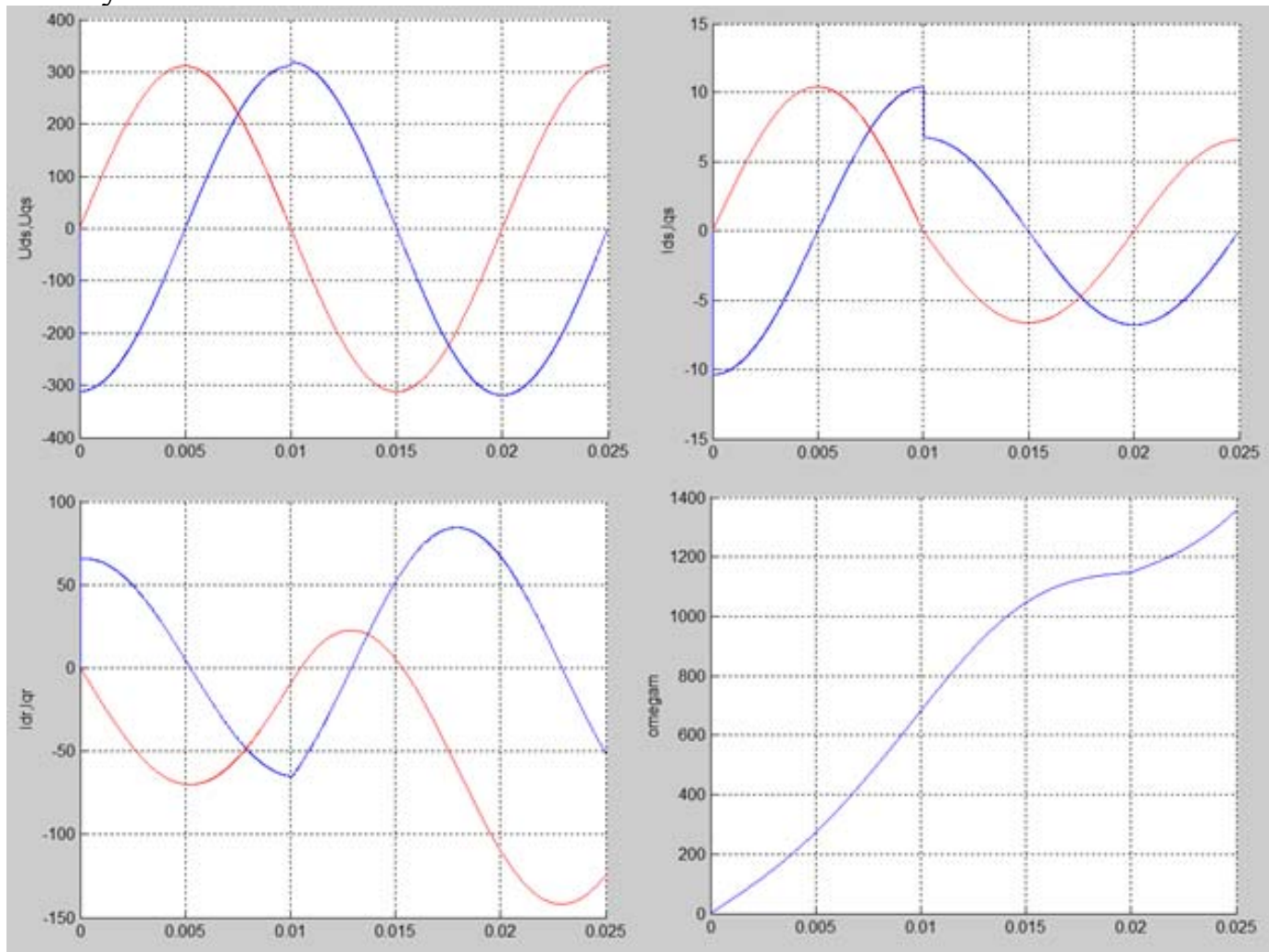

Fig. 2: Charts of the CS with observer operational results at variable disturbances, clockwise: voltage "dq" stator, currents "dq" stator, shaft rotation speed, currents "dq" rotor

Now refer to figure 3, where curves illustrated asked AC disturbance load and assessment of observer. 


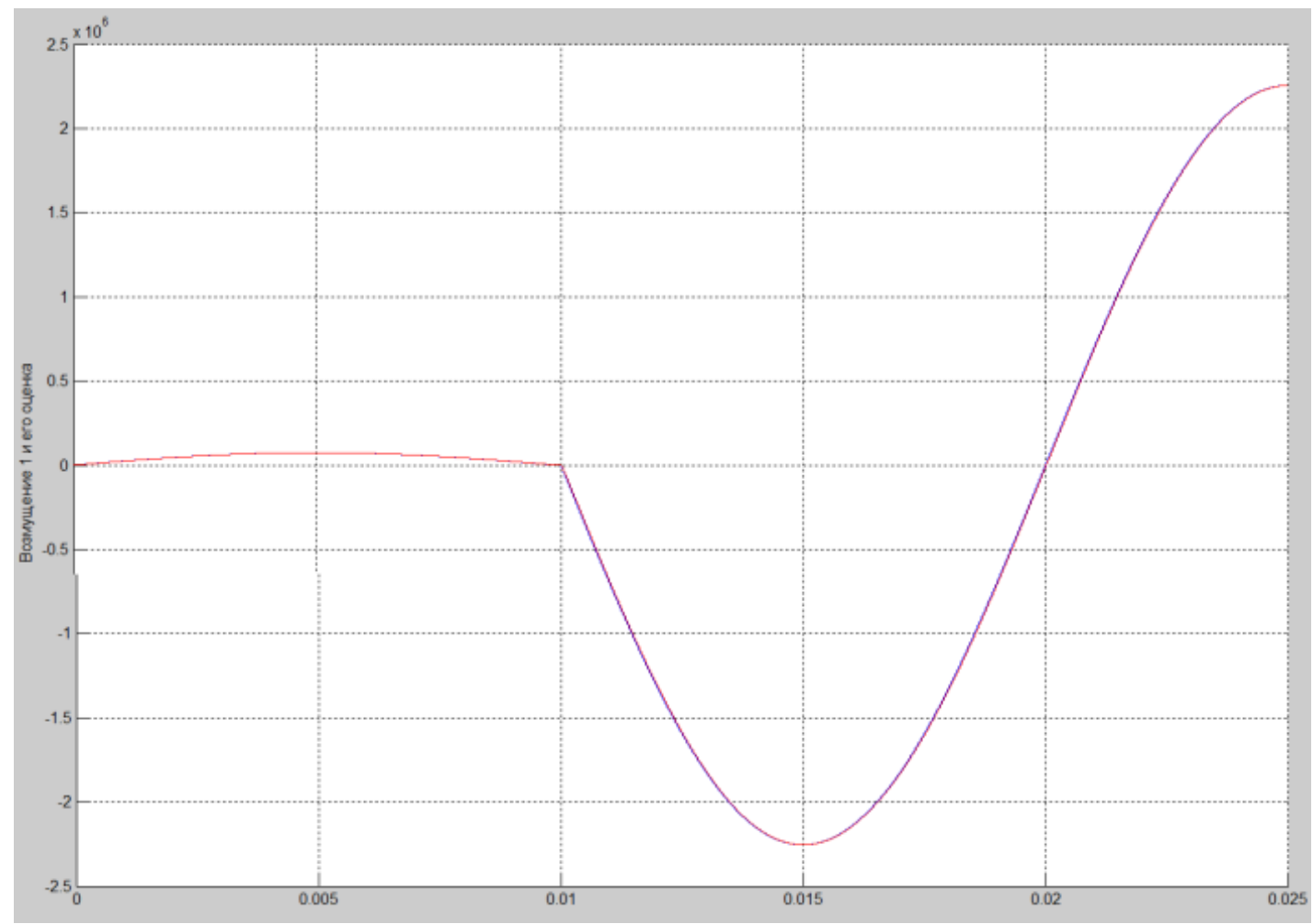

Fig.3: Load disturbance (red) and it's estimation (blue) by observer.

Here electrical load disturbance varies according to given above change and its estimation by the observer similarly changing, and shapes of the two curves are nearly identical. This suggests that the observer estimates disturbances correctly and makes the necessary adjustments in CS work.

\section{Summary}

When analyzing the results of nonlinear adaptive CS with observer modeling, it can be noted that this control system solved the indicated above control problems. The advantages of this CS are the high quality of the generated voltage, and the estimation of nonlinear disturbances with the subsequent adjustment of the control voltage, current, in this particular example, for the current of the stator "dq" axis. The disadvantage is the high demands for the computing power of microprocessor system, on which you will create this CS. It should also be noted that in real conditions, an inverter couldn't instantly change the shape of the control voltage that will affect performance. These issues require further implementation of full-scale experimental studies.

\section{Acknowledgements}

This work was financially supported by Russia's Southern Federal University grant: "Theory and methods of energy-saving control for distributed generation, transportation and electricity consumption systems".

\section{References}

[1] Andrey A. Mazalov. Non-linear control system for wind power plant with DFIG., 2013 International Conference on Renewable Energy and Environmental Technology (ICREET 2013) Applied Mechanics and Materials Vols. 448-453 (2014) pp 1884-1887, Trans Tech Publications, Switzerland.

[2] Pshihopov V.H., Medvedev M.U. Contol of movable objects in certain and indefinite environments. Russia, Moscow (2011). ISBN 978-5-02-037509-3 